\title{
On Wrongs and Crimes: Does Consent Require Only an Attempt to Communicate?
}

\section{Tom Dougherty ${ }^{1}$ ()}

Published online: 27 June 2018

(c) The Author(s) 2018

\begin{abstract}
In Wrongs and Crimes, Victor Tadros clarifies the debate about whether consent needs to be communicated by separating the question of whether consent requires expressive behaviour from the question of whether it requires "uptake" in the form of comprehension by the consent-receiver. Once this distinction is drawn, Tadros argues both that consent does not require uptake and that consent does not require expressive behaviour that provides evidence to the consent-receiver. As a result, Tadros takes the view that consent requires an attempt to communicate, but nothing more. While I have found Tadros's arguments for this conclusion intriguing and challenging, I am yet to be persuaded by them. In this essay, I try to say why.
\end{abstract}

Keywords Consent $\cdot$ Ethics $\cdot$ Law $\cdot$ Wrongs $\cdot$ Crimes $\cdot$ Tadros

Reading Wrongs and Crimes, your awe is inspired by the sheer range of topics that it covers, as well as the sheer number of the arguments offered on any one of these topics. Take the four chapters on consent, for instance. In these chapters, Victor Tadros addresses a huge number of ethical issues about consent. One of these issues concerns the extent to which consent needs to be communicated, and that is what I am going to focus on in this essay. From the fact that there is so much to say in response to only five pages of Wrongs and Crimes, draw your own conclusions about how rich the rest of the book is.

Tadros clarifies the debate about whether consent needs to be communicated by separating the question of whether consent requires expressive behaviour from the question of whether it requires "uptake" in the form of comprehension by the consent-receiver. Once this distinction is drawn, Tadros argues both that consent does not require uptake and that consent does not require expressive behaviour that provides evidence to the consent-receiver. As a result, Tadros takes the view that consent requires an attempt to communicate, but nothing more. While I have found

Tom Dougherty

tjsd3@cam.ac.uk

1 University of Cambridge, Cambridge, UK 
Tadros's arguments for this conclusion intriguing and challenging, I am yet to be persuaded by them. I will try to say why.

\section{What Does Morally Valid Consent Consist In?}

To contextualise Tadros's views on consent, let us briefly survey an enduring debate about what constitutes morally effective consent. To stipulate some terminology, let us say that when a consent-giver succeeds in releasing someone from a duty, she gives "morally valid consent." 1 That is, when $\mathrm{X}$ gives morally valid consent to $\mathrm{Y}$ to perform an action $\mathrm{v}, \mathrm{X}$ releases $\mathrm{Y}$ from a duty that $\mathrm{Y}$ otherwise owed to $\mathrm{X}$ not to perform v. For this consent to be morally valid, certain background conditions have to be met. Plausibly, $\mathrm{X}$ must be acting suitably voluntarily. $\mathrm{X}$ must be a suitably competent agent. And X must be suitably informed. There may be other conditions too. An account of consent ought to clarify these conditions, e.g. by specifying what counts as "suitable" voluntariness, information, or capacity. But even once it has filled in these gaps, the account still needs to say what morally valid consent is. To discuss this question, I will follow Tadros in implicitly assuming that background validity conditions are met. With that implicit assumption, we can frame our central question as the question of what $\mathrm{X}$ must do in order to consent.

In the literature, there are two main types of view. According to Mental Views, morally valid consent consists in some form of mental entity. This entity might be a desire, intention, or choice. According to Behavioural Views, morally valid consent requires some form of outward behaviour. In my opinion, the most plausible Behavioural Views also require some intention on the part of the consent-giver. If a Behavioural View does not require this intention, then the view implies that someone can unintentionally consent. That is an unwelcome result.

Tadros makes an important contribution to this debate by drawing a distinction between different Behavioural Views. ${ }^{2}$ One view requires communication that is successful in the sense that there is "uptake" on the part of the target of the consent. The consent has uptake when the consent is successfully communicated in the sense that the consent-receiver realises that the consent-giver is communicating consent. We can state this view as follows:

\footnotetext{
${ }^{1}$ Some philosophers make the terminological choice to use the term "consent" so that the term necessarily refers to consent that succeeds in releasing someone from a duty. On their usage, someone does not consent, but e.g. merely assents, if she does not succeed in releasing someone from a duty. We find that terminological choice mirrored in some aspects of the law. Nothing substantive hangs on whether we use the terms "morally valid consent" and "morally invalid consent" or we use the terms "consent" and "assent" to mark the substantive difference between morally efficacious consent and morally inefficacious consent. I prefer the former terminology as it allows us to clearly distinguish cases in which someone makes no attempt to consent ("absent consent") from cases in which someone makes an unsuccessful attempt to consent ("invalid consent").

${ }^{2}$ I give my own names to these views and subsequent ones, but I use Tadros's (2016: 206-207) own words when stating their substance.
} 
Uptake View: Consent is an act that requires both an attempt to communicate and uptake.

Tadros points out that someone could hold that morally valid consent requires some form of outward behaviour, while denying that morally valid consent requires uptake. For example, consider the following view:

Public Evidence View: Consent is an act that requires public expression that gives the person to whom consent is given sufficient evidence of the intention to release him from a consent-sensitive duty that he is under.

Previous discussions of consent had tended to conflate the Uptake View and Public Evidence View, and Tadros's discussion brings welcome clarity to the debate. ${ }^{3}$

On the other side of the debate, Tadros argues that the most plausible Mental Views should conceive of consent as a mental act. One such view is the following:

Non-Communicative Mental View: Consent is an act that can be performed purely mentally, without any attempt to communicate.

An alternative view requires this attempt to communicate:

Attempted Communication View: Consent is an act that requires an attempt to communicate.

As a contingent matter of fact, an attempt to communicate will normally bring with it some form of outward behaviour. But if someone had odd beliefs, then she can attempt to communicate without performing any behaviour. For example, Tadros (2016: 209) considers

... a person who thinks that she can communicate telepathically. She can consent without any public expression of consent. Her attempt to communicate telepathically is sufficient. But if a person knows that she cannot communicate with another person, she cannot consent.

Since the Attempted Communication View allows that this deluded person can consent purely mentally, I take the Attempted Communication View to be a Mental View. Admittedly, it is a sophisticated version that allows that as a contingent matter of fact a rational person's attempt to communicate will nearly always involve some behaviour.

\footnotetext{
3 At roughly the same time, Neil Manson (2016) drew a similar distinction.
} 


\section{Tadros's Arguments Against the Uptake View}

Although on balance Tadros favours the Attempted Communication View, he does not take a "strong stance" between it and the Non-Communicative Mental View. His main priority is to argue against the Uptake View and the Public Evidence View. Tadros offers three arguments against the Uptake View. Let us take each in turn.

\subsection{The Mumble Argument}

Tadros's first argument concerns the following type of case:

Mumbled Consent: Smith asks for Jones's consent to borrow Jones's shirt. Jones mumbles something. Smith is not sure what Jones has said and so is not sure whether Jones has consented. ${ }^{4}$

If we stick closely to the letter of Tadros's argument, then we could reconstruct it as follows:

P1. Smith is unsure whether Jones has validly consented.

$\mathrm{C} 1$. Therefore, it must be true or false that Jones has validly consented.

C2. Equivalently, there is something, Jones's valid consent, about which Smith is unsure.

C3. Therefore, Jones's consent is independent of whether Smith believes that Jones has consented.

But if C3 is true, then uptake is unnecessary for valid consent. So we can conclude that the Uptake View is false.

On this literal interpretation, the argument would be invalid. In general, we cannot draw conclusions about what is morally the case from premises about a person's uncertainty about what is morally the case. The reason why we cannot validly make such an inference is that the person in question might simply be morally confused. If this person is morally confused, then her beliefs or uncertainty tell us little about what the moral world is like. To see this, consider a normative power that does require uptake. Let us assume for the sake of argument that the power of giving commands is a normative power that requires uptake. ${ }^{5}$ Even if that assumption is true, it may still be that Smith fails to believe that it is true. Instead, Smith might mistakenly think that the normative power of giving commands does not require uptake. As a result, Smith might be unsure whether a

\footnotetext{
${ }^{4}$ I omit from Tadros's description of the case the stipulation that X "thinks" that $\mathrm{Y}$ has consented. If this addition is made, then the case is no longer a counterexample to the Uptake Condition, as there would be uptake on X's part.

5 Feel free to substitute throughout another normative power besides command. My argument requires only the assumption that there is at least one normative power that requires uptake.
} 
mumbled order is a genuine order. But Smith's uncertainty is consistent with our initial assumption that orders require uptake.

There is a more charitable interpretation of the argument, and in personal correspondence, Tadros has told me that this interpretation is what he had in mind. His thought was not just that Smith is unsure whether Jones has consented. In addition, he thought Smith was warranted in being unsure. So on this interpretation, we should replace $\mathrm{P} 1$ with $\mathrm{P} 1 *$ :

$\mathrm{P} 1 *$. Smith is warranted in being unsure whether Jones has consented.

How should we continue the argument? On the basis of this correspondence with Tadros, I suggest:

P2. Smith is warranted in being unsure whether Jones has consented only if Smith does not know of any facts that make it the case either that a) Jones consents; or b) Jones does not consent.

From these premises, we can infer:

$\mathrm{C} 1 *$. Smith does not know of any facts that make it the case that Jones does not consent.

Now it is stipulated as part of the case that Smith is not sure what Jones has tried to say. So we can assume:

P3. Smith knows that he lacks uptake.

Finally, from $\mathrm{C} 1$ and $\mathrm{P} 3$, we can infer:

C2*. Therefore, Smith's lack of uptake does not make it the case that Jones does not consent.

Of course, the Uptake View implies that Smith's lack of uptake would make it the case that Jones does not consent. So C2* would show that the Uptake View is false.

On this interpretation of Tadros's argument, it is clearly valid. But it will be contentious whether it is sound. If people are antecedently sympathetic to the Uptake View, then I suspect they will be reluctant to grant P1*. They will hold that once Smith is aware that Jones is mumbling, Smith can conclude that there is no uptake. They will maintain that if Smith can conclude that there is no uptake, then Smith has warrant for concluding that Jones does not validly consent. So instead of granting P1*, I suspect that they will only be willing to grant:

(1) It is appropriate for Smith to be unsure whether Jones has attempted to communicate consent. 
But (1) does not imply P1*, and (1) does not offer the prospect of an argument against the Uptake View. So my sense is that direct intuitive reflections on the Mumbled Consent case are likely to lead to a dialectical stand-off. Those antecedently opposed to the Uptake View will see the case as nicely illustrating and confirming their reasons for rejecting the view. Those antecedently sympathetic to the Uptake View will see the case as offering no threat to the Uptake View. This dialectical impasse does not imply that Tadros has offered an incorrect analysis of the Mumbled Consent case. But the dialectical impasse does suggest that direct appeals to intuitions about the Mumbled Consent case are unlikely to move the debate forward. If so, then the debate about whether to accept the Uptake View will have to be resolved on other grounds.

\subsection{The Delayed Consent Argument}

Tadros's second argument concerns the following case:

Delayed Consent: On Monday, Bill asks Sally if he can borrow her car on Wednesday. On Tuesday, Sally emails Bill to say that he can. Bill does not read the email until Thursday.

About this case, Tadros argues that the Uptake View implies that Sally only consented on Thursday to Bill borrowing the car, by which time this consent was too late. Tadros claims that the better view is that Sally consented on Tuesday, but Bill did not find out until Thursday.

Perhaps some readers will antecedently agree that Tadros's preferred view is better, but I suspect many will be at least ambivalent. While Tadros does not say why his preferred view is better, he does suggest it fits better with his preferred view of promises. To illustrate this connection with promises, let us consider the following case, which features in Hallie Liberto's (2018: 17-18) excellent discussion of delayed promises.

\section{Delayed Receipt}

Adam I just got your wonderful letter! Thank you so much. I knew our relationship was ready for this step-even if we're living apart for the semester

Bertha I knew how much it meant to you that I promised to be monogamous. I'm sorry that I didn't commit to this before you left. I just had to think it over a little

Adam When did you decide? What made you change your mind?

Bertha Well, right before I wrote the letter. I woke up thinking about you on Monday. It was such a strong feeling. I thought a letter would be the most meaningful way to make you that promise. I sent it right away

Adam Well. Thank you. It means the world to me, obviously

Bertha You just got it today though, right?

Adam Right 
Bertha Oh good. I was a little worried that it would get to you early

Adam Why?

Bertha Well, I had one last romp with Willis, my ex, last night. You see, I was confident that the letter wouldn't get to you until today

Adam Wait, what?

Bertha That's all

Adam You spent a night with Willis after writing that solemn promise to me, and sending it to me? What sort of promise is that?

Bertha Well, I didn't plan to see Willis when I wrote you the letter. But when I ran into him, it occurred to me that you hadn't gotten the letter yet. The promise is solemn. It started this morning, when you got the letter, or maybe just now, when you told me you were glad

Adam (sarcastically) Is that why a letter seemed like "the most meaningful way to make the promise ...?"

About a case like this, Tadros would claim that Bertha promised when she wrote the letter on Monday, but Adam only discovers the promise when he reads the letter. For this reason, Tadros claims that promises do not require uptake.

In denying that promises require uptake, Tadros is adopting an idiosyncratic view of promises. As Liberto (2018) notes, most contemporary theories of promises hold that promises require uptake (Thomson 1990; Scanlon 1998; Darwall 2011; Friedrich and Southwood 2011; Owens 2012). But if someone holds that promises require uptake, then she has to say something about the Delayed Receipt case. One option is to deny that Bertha does break her promise. If we take this option, then we can say that Bertha has misled Adam or that she has acted inconsistently with the sentiment that she expressed to him in the letter. But Liberto does not take this option, as she shares the intuition that Bertha has broken a promissory obligation. Still, Liberto shows how this claim can be reconciled with the view that promises require uptake. She does so with the following elegant solution to the puzzle:

... promissory obligation can be generated before a promise has been completed. All that is required for promissory obligation to arise (related to uptake), is that (a) a promise has been launched, and (b) that it is ever the case that uptake occurs. This means that a promisor can incur a promissory obligation before uptake has occurred. Also, a promisor can sometimes be in a position in which she does not know whether she is under promissory obligation, because she does not know if her promise, when received or understood by her promisee, will be uptaken. The promisor can usually retract the promise before uptake. In this way, her promissory obligation before uptake has occurred is different than afterward, because the promisor can be the one to release herself from the obligation. (Liberto 2018: 20-21)

Liberto's view implies that the promise is only completed on Thursday when Adam reads the letter. But holding fixed the fact that Adam will read the letter on Thursday, Bertha's normative situation has changed from the moment that she sends the letter. 
There's much to like about Liberto's view. It allows her to explain why an adult can hold someone to account for a promise that was made to her before she acquired rational agency. Liberto's view also explains why a promise is generated by a shopkeeper putting up a sign guaranteeing cookies for whoever is the first person to enter her store the following day. But the most compelling reason to accept Liberto's view comes from considering the possibility that an expression of a promise might be intercepted. Liberto (2018: 22) notes that "if Bertha had run to the post office to intercept the letter, and succeeded, she would not be under promissory obligation." Liberto's view implies this conclusion "as this [interception] would have prevented Adam from ever uptaking the promise." Liberto goes on to make the following important point: "In fact, after her romp with Willis, Bertha should have attempted just such an interception." If post-romp, Bertha had intercepted the letter, then she would not have breached her promissory obligation. On the other hand, if postromp, Bertha's letter reaches Adam, then she would have breached her promissory obligation. This shows that whether the romp constitutes a breaking of a promissory obligation depends on whether there is uptake later. This result by itself shows that Liberto's view of promises is correct and promises do require uptake.

For these reasons, I am persuaded by Liberto's account of promissory uptake. It extends naturally to an analogous view of delayed consent. Suppose for the sake of argument that all the other relevant considerations end up stacking up in favour of the Uptake View, and so we are otherwise inclined to hold that consent requires uptake. On this assumption, we should say that, just as Adam's subsequent uptake of the promise can make it the case that Bertha was previously obliged not to have sex with Willis, Bill's receipt of Sally's consent on Thursday makes it the case that he was permitted to use the car on Wednesday. Of course, it is up for grabs whether we should assume that all the other relevant considerations favour the Uptake View. My point here is only that cases like Delayed Consent give us no independent reason to reject the Uptake View.

\subsection{The Control Argument}

Tadros's third argument appeals to a big picture idea about why we owe others duties from which they can release us by giving their consent. Tadros (2016: 207) floats the following possible explanation of why we have consent-sensitive duties:

One explanation why $\mathrm{X}$ owes $\mathrm{Y}$ a consent-sensitive duty not to $v$ is that it is valuable to $\mathrm{Y}$ that she has control over the duties that $\mathrm{X}$ owes her.

Tadros notes that the Uptake View would reduce how much control Y has over the duties that $\mathrm{X}$ owes to her. The Uptake View implies that $\mathrm{Y}$ fails to release $\mathrm{X}$ from such a duty, when $\mathrm{Y}$ tries her best but fails to secure uptake from $\mathrm{X}$. Then, despite Y's best efforts, X's duty remains in place.

This explanation focuses on Y's interest in controlling the duties that $\mathrm{X}$ owes to her. As such, it is an example of a "normative interest" account of consent (Owens 2012: 175). However, we do not have to endorse a normative interest 
account in order to be moved by the considerations that underlie Tadros's argument. Consider the following schema for offering an alternative explanation:

The fact that $\mathrm{X}$ owes $\mathrm{Y}$ a consent-sensitive duty not to $v$ is explained by the fact that it is appropriate that $\mathrm{Y}$ has control over the duties that $\mathrm{X}$ owes her.

The fact that it is appropriate that $\mathrm{Y}$ has control over the duties that $\mathrm{X}$ owes her is explained by other facts.

That proposal is only schematic, as it fails to say what these "other facts" are. But even the schematic explanation is enough to entail that there is an important link between the way consent operates and a consent-giver's control over another person's duties. That link by itself puts pressure on the Uptake View, given that the Uptake View would reduce how much control that a consent-giver has over the duties that a consent-receiver owes to her.

I am persuaded by Tadros that the Uptake View reduces the extent to which a consent-giver controls the duties of a consent-receiver. In establishing this point, Tadros makes precise a link between autonomy and consent that others have gestured at. Heidi Hurd (1996) and Kimberly Ferzan (2016) have defended Mental Views on the grounds that our consent manifests and protects our autonomy, without elaborating the proposed connection between consent and autonomy. Tadros's proposal offers us a way of filling in the details. Suppose that an agent is more autonomous, the greater her capacity for self-governance. Suppose also that the agent has greater self-governance, the more control that she has over aspects of her life. By rejecting the Uptake View, a moral theory would increase the extent to which it implies that an agent is autonomous over the moral sphere of her life. So, rejecting the Uptake View ensures a closer link between autonomy and consent.

While Tadros is correct to claim that the Uptake View has this disadvantage, it is unclear to me how serious the disadvantage is. Following Alan Wertheimer (2003), we should distinguish two ways in which we might control whether we consent. First, we might ensure that we are not consenting when we intend not to be consenting. This would be a sense in which we had "negative autonomy":

Negative Autonomy: The capacity to ensure that one is not validly consenting.

The Uptake View does not limit our negative autonomy. In other words, the Uptake View does not imply that we can accidentally consent. This is because the Uptake View requires an "attempt to communicate" in order for there to be valid consent. If someone is attempting to communicate consent, then she is not accidentally consenting.

However, Tadros's argument shows that the Uptake View does limit another part of our autonomy. This is our correlative ability to ensure that we are consenting when we intend to be consenting:

Positive Autonomy: The capacity to ensure that one is validly consenting. 
Our positive autonomy is limited by the Uptake View, since the failure of uptake may be beyond our control. We can fail to successfully consent despite our best efforts.

Still, we have to wonder how much of a problem this limit to our positive autonomy would be in the real world. I speculate that, in most actual cases, consent-givers will be able to secure uptake, even if sometimes this requires that they invest a bit of time and effort to make sure they communicate successfully. If I am right, then this may mean that the Uptake View's limit on our positive autonomy is not very important in practice. It is difficult to evaluate this line of reasoning, however. This is because it is hard to say how much a theory of consent must be sensitive to the actual frequency of various types of problem. My hunch is that this matters, but I do not know how to justify this hunch to anyone who feels differently.

\section{The Valuable Opportunity Argument}

So far, we have been looking at Tadros's arguments against the Uptake View. Now let us turn to Tadros's argument against the other Behavioural View that he considers:

Public Evidence View: Consent is an act that requires public expression that gives the person to whom consent is given sufficient evidence of the intention to release him from a consent-sensitive duty that he is under.

Tadros's argument is based on the following case:

Foreign Lovers: Brenda consents to sex with Ahmed in a language that Brenda thinks Ahmed understands, but he does not. Because Ahmed does not believe Brenda consents, they do not have sex. (Tadros 2016: 207)

Tadros (2016: 208) says the claim that Brenda has not validly consented is "powerfully counterintuitive." I suspect that some people's intuitions are likely to differ. So if someone was otherwise attracted to the Public Evidence View, then what reason does she have to reject it? Tadros (2016: 208) offers such a reason in his claim that both Brenda and Ahmed have a ...

... powerful interest in Brenda having consented. The value of this might be partly to do with the relationship that she forms with Ahmed by doing this ... [even if they never have sex], they might value her having [given consent] and not merely tried to do this.

Let us call this the "Valuable Opportunity Argument." While Tadros offers this argument in the course of critiquing the Public Evidence View, we should note that it would also cut against the Uptake View. Since Ahmed does not uptake Brenda's consent, the Uptake View implies that they are thwarted in their interest in Brenda having consented. 
In response to Tadros, we should ask why the following type of inference is valid:

P1. It would be valuable for Brenda to have permitted Ahmed to have sex simply in virtue of her decision to communicate.

C. Therefore, Brenda permitted Ahmed to have sex simply in virtue of her decision.

It does not seem as if we can generally make the following inference:

$\mathrm{P} 1$. It would be valuable for $\mathrm{X}$ and $\mathrm{Y}$ if $\mathrm{X}$ is permitted to do A to $\mathrm{Y}$.

C. Therefore, $\mathrm{X}$ is permitted to do A to $\mathrm{Y}$.

So why is the inference valid in the special case of consent? There may well be things to say here, but I am not sure how the argument is meant to go.

To press the point, we should ask why Brenda and Ahmed should place so much value on the existence of valid consent. After all, there are lots of other things that they could value. They could value the fact that Brenda wanted to have sex with Ahmed. They could value the fact that Brenda tried to permit Ahmed to have sex. These facts say a lot about Brenda's attitudes towards Ahmed, the meaning that she placed on their relationship and how she saw the encounter in which they nearly had sex. Given Ahmed and Brenda have all these things to mutually value, why should they be so concerned about the moral permissibility of a sexual encounter that never took place? If they were moral philosophers, they might idiosyncratically value moral permissibility in particular. But if they are just normal people going about their lives, then they would likely be content with the range of other things that they can value.

This is an example of a broader challenge facing anyone who wants to ground facts about consent in facts about values. For the overall view to be fully persuasive, it needs to supply a suitably precise framework that explains why the ethics of consent are shaped in this particular way by these particular values, in the context of all the other morally relevant facts. This sort of explanatory demand is giddying. But if an account fails to meet the demand, then it is unlikely to move the debate forward. While Tadros has opened up an interesting line of inquiry, I do not think his remarks meet this demand. So while I am intrigued by the Valuable Opportunity Argument, I am yet to be convinced.

\section{The Deliberation and Duties Argument}

So far we have looked at Tadros's arguments against the Uptake View and the Public Evidence View. Once these views are ruled out, Tadros is left with the Non-Communicative Mental View and the Attempted Communication View. Out of these, he argues for the Attempted Communication View. How does he do so?

Tadros's argument begins in Chapter 3 with his big picture view of the role of morality and our duties. Tadros notes that there is an important difference between having decisive reason to perform an action, and being morally required to perform 
the action. For example, someone might have decisive reason to order the tastiest dish on the menu. If she were to knowingly order a different dish, then she might be akratic or irrational. But she would not be acting immorally. ${ }^{6}$ Accordingly, Tadros argues that an account of morality must explain the difference between having most reason to perform an action and being morally required to perform it.

Tadros argues that this difference is best explained motivationally. To understand what is distinctive of morality, we need to understand the motivational force that duties have. This motivational force gives these duties a distinctive role in our practical reasoning. Tadros refers to this as the "problem of moral motivation." As a solution to this problem, Tadros (2016: 28-29) proposes that moral obligations motivate in virtue of constraining an agent's reasoning. Tadros explicates the notion of a constraint with an example. A ship's captain may be morally required to use a fair lottery to decide who can escape a sinking ship, rather than use a rigged lottery to ensure her own child is saved, even though she has reason to value the outcome in which her own child is saved. Generalising, Tadros's view is that even when virtuous people have reason to value certain outcomes, it may be that morality constrains them from performing actions that would lead to these outcomes. This leads to Tadros's (2016: 208) view that the "primary function of X's duties is to constrain $\mathrm{X}$ 's practical reasoning." Let us call this the Deliberative View of Duties.

Tadros argues from the Deliberative View of Duties to the Attempted Communication View. Tadros (2016: 208) maintains that on his view of duties ...

... when $\mathrm{Y}$ consents to $\mathrm{X}$ ving, she must execute an intention to affect $\mathrm{X}$ 's practical reasoning: she releases $X$ from a constraint that he would otherwise have not to $v$ because of what he owes to her. But she cannot execute such an intention without intending to communicate with $\mathrm{X}$. This is because it would be impossible for her to alter the role that ving has in X's practical reasoning without communicating with $\mathrm{X}$. She cannot intend to do something that she believes is impossible to do. Hence, $\mathrm{Y}$ consents only if she intends to communicate to $\mathrm{X}$ that he has the option to $v$.

On these grounds, Tadros defends the Attempted Communication View. Let us call this the "Deliberation and Duties Argument."

It is not entirely clear to me how this argument is meant to work. One way to interpret the argument is as follows. Tadros holds that duties affect someone's practical reasoning. Perhaps, he is assuming that we all grasp this point. As a result, Tadros may be maintaining that if someone is trying to affect another person's duties, then she must be trying to affect that person's practical reasoning. From this, we could infer that if someone is trying to give consent to another person, then she must be trying to causally affect that person's practical reasoning. So if a consentgiver is rational and she is aware that communication is necessary for affecting the

\footnotetext{
${ }^{6}$ In conversation, Tadros has pointed out to me that this result cannot be accommodated by an act-utilitarian, who claims that an act is morally wrong if the act fails to maximise the total amount of happiness. By choosing the less tasty dish, she would be performing an act that fails to maximise the total amount of happiness in the world.
} 
consent-receiver's practical reasoning, then she will attempt to communicate to the consent-receiver. Since this interpretation of Tadros's argument appeals to what must be going on in the mind of a consent-giver, let us call it the "psychological interpretation."

On the psychological interpretation, Tadros's argument fails. There is no warrant for the assumption that if someone is trying to affect another person's duties, then she must be trying to affect that person's practical reasoning. Consider Tadros's acknowledgement that it is contentious to think of duties as tied closely to practical reason. Others think of these duties in terms of accountability. They think that we hold each other to account for performing or failing to perform these duties. If someone denies Tadros's Deliberative View of Duties, then this person could attempt to affect another person's duties, without thereby attempting to affect that person's practical reasoning.

A similar line of reasoning shows why there is no warrant for the assumption that if someone is trying to consent, then she must be trying to causally affect a consentreceiver's practical reasoning. To see this, we need only notice that there are people who sincerely hold the Non-Communicative Mental View. Ferzan is one. On Ferzan's (2016) view, someone consents to another person's action by deciding that the action is okay with her. Ferzan is aware that this decision does not require an attempt to communicate the decision. So Ferzan could attempt to consent simply by making the decision and not trying to communicate the decision. Take Ferzan's example of consenting to a neighbour crossing her lawn. We could imagine that Ferzan is watching someone about to cross her lawn, but cannot communicate with that person before she crosses the lawn. Ferzan could still decide that the lawn-crossing is okay with her. By doing so, Ferzan would thereby be trying to consent to the lawncrossing. So even if someone is trying to give her consent, it does not follow that she is trying to communicate that she is consenting.

There is another way of interpreting Tadros's argument. Tadros might hold that because a duty must engage the duty-holder's practical reasoning, this person must have epistemic access to the duty. It is hard to say what exactly this epistemic access would have to be. One proposal is that the normative principles governing someone's duties should ensure that these duties are easy for the duty-holder to discover. These principles would also apply to consent, since consent releases people from duties. Following this line of thought, we might conclude that the principles governing consent should ideally imply that a consent-receiver can discover when she has received morally valid consent. Without the consent-giver attempting to communicate, the consent-receiver would be unable to discover whether she has received morally valid consent. So we have reason to reject the Non-Communicative Mental View in favour of the Attempted Communication View. Let us call this the "epistemic interpretation" of the argument.

On the epistemic interpretation, Tadros's argument is valid, and it puts pressure on the Non-Communicative View: the Attempted Communication View would ensure that the duty-holder has better epistemic access to her duties. But now there is a new problem lurking for Tadros: the epistemic interpretation also puts pressure on the Attempted Communication View. The Public Evidence View and the Uptake View ensure that the duty-holder has even better epistemic access 
to her duties. Indeed, the Uptake View implies that whenever consent changes someone's duties, this person's deliberation can always take this change into account. So if Tadros's Deliberative View of Duties counts in favour of consent being epistemically accessible, then the Deliberative View of Duties would most support the Uptake View.

Tadros (2016: 208) appears to anticipate this worry, as he asserts that this attempt to communicate need not be successful:

But she can execute an intention to release $\mathrm{X}$ from a duty without actually affecting $\mathrm{X}$ 's practical reasoning. By attempting to communicate to $\mathrm{X}$ that she permits him to $v$ she alters the facts that $\mathrm{X}$ has a reason to respond to. If he fails to recognize that she has done this, he fails to respond to something that he has reason to respond to. So by attempting to communicate her permission to $X$, she already succeeds in releasing him from his duty. After she has done so, he may or may not realize that something relevant to his practical reasoning has changed.

But while Tadros makes this assertion, he does not show that he has good reason for doing so. Without providing any further justification, it seems ad hoc to take the intermediary position of favouring an attempt at communication on the basis of epistemic considerations. If the Deliberative View of Duties implies that all else equal a duty-holder should be able to factor her duties into her decision-making, then it seems that the Deliberative View of Duties best supports the Uptake View.

\section{Conclusion}

Let me sum up the main conclusions that I have argued for in this essay. I have argued that the Mumble Argument (Sect. 2.1) and the Delayed Consent Argument (Sect. 2.2) are unlikely to land significant blows on the Behavioural Views, as these views have plausible replies. Meanwhile, on what seems to me its most plausible interpretation, the Deliberation and Duties Argument (Sect. 4) does not only support the Attempted Communication View over the Non-Communicative Mental View; it also favours the Behavioural Views over both those Mental Views. More promising for the Mental Views, the Control Argument (Sect. 2.3) does identify a distinctive advantage for these views: these views increase our positive autonomy to give consent, when we so intend. However further work is needed to establish how significant an advantage this is. Meanwhile, the Valuable Opportunity Argument (Sect. 3) is intriguing, and may have significant force. But to become fully cogent, the argument would need to explain why people should value giving consent (as opposed to e.g. being willing to have sex), and it would need to be situated in a developed framework that articulates the relationship between underlying values and consent.

So in conclusion, while many of these arguments have promise, I think the jury is still out. I look forward to these arguments shaping philosophical discussions of consent in the foreseeable future. Philosophical research on foundational 
issues concerning interpersonal consent is in fairly early days, and Tadros has elevated it to new levels of rigour.

Acknowledgements Thanks to Victor Tadros for helpful comments on this essay. The research for this essay was financially supported by an Early Career Leadership Fellows Award from the Arts and Humanities Research Council, Council Reference: AH/N009533/1.

Open Access This article is distributed under the terms of the Creative Commons Attribution 4.0 International License (http://creativecommons.org/licenses/by/4.0/), which permits unrestricted use, distribution, and reproduction in any medium, provided you give appropriate credit to the original author(s) and the source, provide a link to the Creative Commons license, and indicate if changes were made.

\section{References}

Darwall, Stephen, 2011, "Demystifying Promises", in Sheinman 2011.

Friedrich, Daniel, and Nicholas Southwood, 2011, "Promises and Trust", in Sheinman 2011.

Hurd, Heidi, 1996, "The Moral Magic of Consent", Legal Theory, 2(2): 121-146.

Ferzan, Kimberly, 2016, "Consent, Culpability, and the Law of Rape", Ohio State Journal of Criminal Law, 13(2): 397-439.

Liberto, Hallie, 2018, "Promises and the Backward Reach of Uptake", American Philosophical Quarterly, 55(1): 15-26.

Manson, Neil, 2016, "Permissive Consent: A Robust Reason-Changing Account", Philosophical Studies, 173(12): 3317-3334.

Owens, David, 2012, Shaping the Normative Landscape, Oxford: Oxford University Press.

Scanlon, Thomas M., 1998, What We Owe to Each Other, Cambridge, MA: Harvard University Press.

Sheinman, Hanoch (ed.), 2011, Promises and Agreement: Philosophical Essays, Oxford: Oxford University Press.

Tadros, Victor, 2016, Wrongs and Crimes, Oxford: Oxford University Press.

Thomson, Judith Jarvis, 1990, The Realm of Rights, Cambridge MA: Harvard University Press.

Wertheimer, Alan, 2003, Consent to Sexual Relations, Cambridge: Cambridge University Press. 